\title{
La persistencia de las creencias prehispánicas en las misiones jesuíticas de Sonora: los elementos de diseño en la fachada de la iglesia de Opodepe
}

Robert H. Jackson*

\section{Recibido: 19 de abril de 2014}

Evaluado: 18 de mayo de 2014

En el Siglo XVI misioneros de las diferentes órdenes iniciaban una campaña de ła evangelización de las poblaciones indígenas de México, con diferentes resultados. Los misioneros, que creían que la cultura europea y la religión católica eran superiores a la cultura indígena, también pensaban que el bautismo significaba la conversión a la nueva fe por los indígenas. Sin embargo, la realidad era distinta. Las creencias indígenas eran más flexibles que las católicas. Los misioneros clasificaban la persistencia de creencias prehispánicas como idolatría y apostasía, pero en la lógica indígena no existía una contradicción en incluir creencias católicas en su propio sistema de creencias ${ }^{1}$.

La evidencia de la persistencia de las prácticas religiosas nativas junto con el catolicismo proviene de diferentes fuentes. La Inquisición investigó la evidencia de la idolatría y la apostasía, y los misioneros escribieron sobre el problema. Las pruebas documentales, sin embargo, no son el único medio de prueba de la persistencia de las prácticas religiosas nativas. Las iglesias y otras estructuras de los nuevos complejos sagrados que los misioneros habían construido, contenían diferentes tipos de pruebas dejadas por los indígenas que levantaron los edificios y los artistas que las decoraban. La iglesia franciscana de Santiago Tlatelolco (Distrito Federal, México), por ejemplo, contiene una piedra grabada con el rostro de Tláloc, el dios de la lluvia. La colocación de la piedra no fue un accidente, y en la década de 1580 funcionarios de la iglesia comenzaron a preocuparse por cómo los nativos prestaban demasiada atención a las piedras grabadas colocadas en las iglesias. El tercer Concilio de la iglesia mexicana ordenó la remoción de las piedras grabadas ${ }^{2}$. Artistas nativos que decoraban las iglesias

\footnotetext{
* Doctor en Historia de América Latina por la Universidad de California, Berkeley.

${ }^{1}$ Para un estudio reciente de la persistencia de las prácticas religiosas indígenas del centro de México ver Jackson, 2013a: 12-28. Para un estudio de la dinámica de la campaña de evangelización del Siglo XVI en el centro de México y a lo largo de la frontera chichimeca ver Jackson, 2013b. Para un análisis comparativo de las misiones en las fronteras de la América española ver Jackson, 2009: 328-347.

2 Jackson, 2013a: 21-24.
} 
y estructuras asociadas incorporaban iconografía prehispánica en lo que aparentemente eran imágenes cristianas. Un ejemplo es la inclusión de los glifos del habla y de la canción en el llamado programa de murales del jardín del paraíso en el claustro bajo de la misión agustina de Malinalco (Fig. 1) (Estado de México). La inclusión de los glifos convirtió el programa de murales en una canción ritual de la flor. La práctica continuada de la danza ritual era una manifestación más de la persistencia de la religión prehispánica, como en el caso de las poblaciones indígenas que viven en las misiones en Texas ${ }^{3}$.

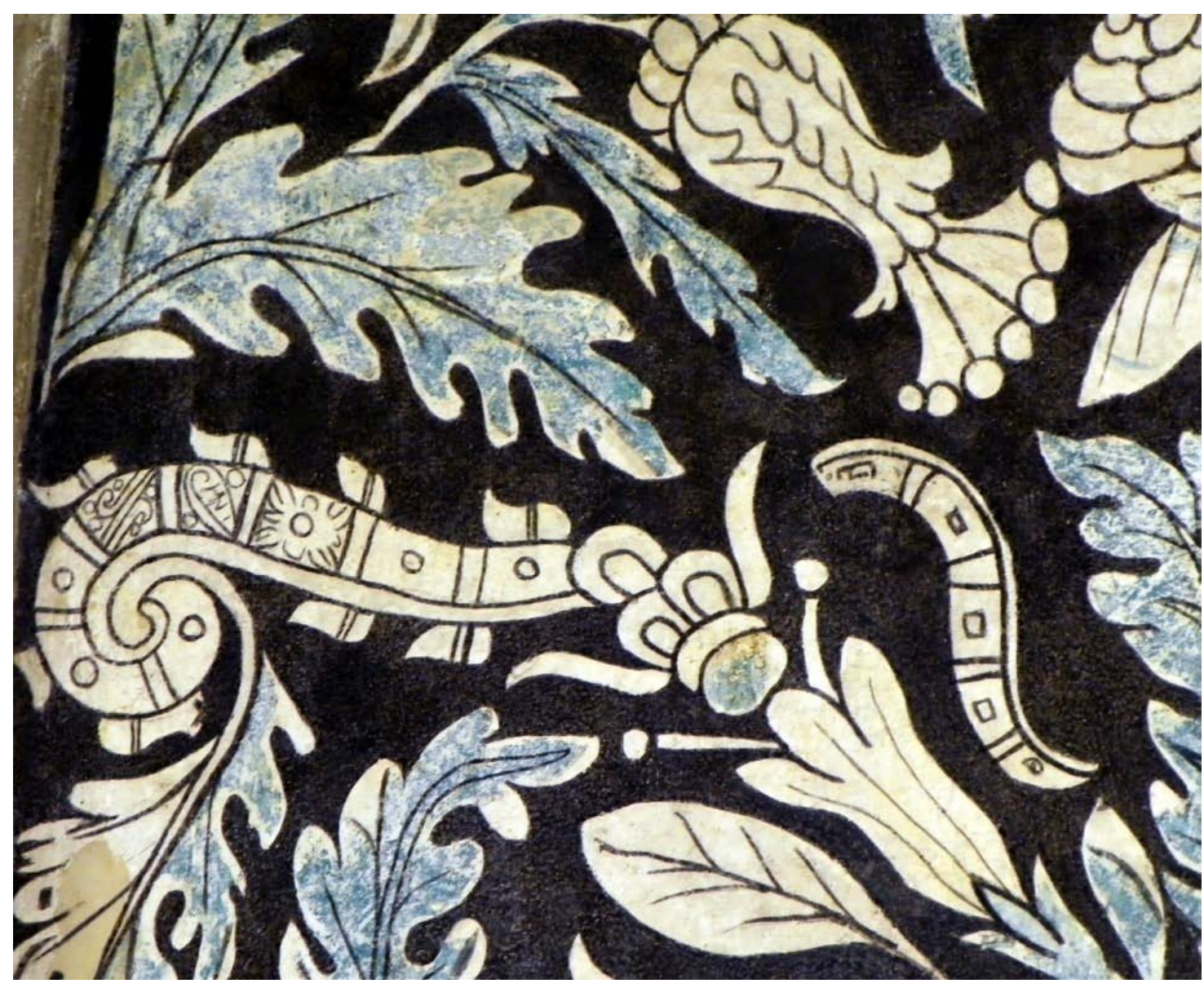

Fig. 1. Un glifo de canción y discurso en el mural del claustro bajo mural cámara acorazada en Malinalco (Estado de México, México).

¿Hay evidencia de la persistencia de la religión prehispánica en las misiones de los jesuitas que se establecieron en el centro de Sonora, en el siglo XVII?. La incorporación de la iconografía religiosa asociada con las creencias religiosas prehispánicas no se limitaba a las regiones del centro de México evangelizadas en el siglo XVI. También hay evidencia de la persistencia de la religión prehispánica entre los agricultores sedentarios que vivían en las misiones que los jesuitas establecieron en el centro de Sonora en el siglo XVII. Muchas de las iglesias de los jesuitas y más tarde franciscanos, construidas en los siglos XVII y XVIII, han experimentado cambios arquitectónicos posteriores que han destruido la evidencia de la persistencia de las prácticas religiosas tradicionales. Una excepción es el elemento de diseño de la fachada

\footnotetext{
${ }^{3}$ Jackson, 2005: 244-248.
} 
de la iglesia de Nuestra Señora de la Asunción en Opodepe, situada en el río San Miguel en el centro de Sonora. Un análisis de los temas que aparecen en el elemento de diseño demuestra que los artistas nativos utilizaron la fachada de la iglesia como una superficie para reproducir el mismo tipo de temas rituales encontrados en petroglifos prehispánicos encontrados en Sonora y otras partes de México, y lo que hoy es el suroeste de Estados Unidos.

Los jesuitas establecieron una misión en Opodepe en 1649 entre los Tehuima (Ópata). El distrito de la misión Opodepe consistió en dos y en ocasiones tres diferentes comunidades, dependiendo del personal que disponían para las misiones. En 1716, por ejemplo, el jesuita establecido en Opodepe y en la comunidad Eudebe Cucurpe, ambas situadas al norte de Opodepe en el río San Miguel, también tenían la responsabilidad de "Tuape" ${ }^{4}$ Los jesuitas había establecido una misión en Cucurpe, más o menos al mismo tiempo que en Opodepe, y hubo períodos en que también no había suficientes misioneros para Cucurpe. En 1716 Cucurpe no tenía un misionero residente.

La fachada de la iglesia Opodepe conserva partes de un elemento de diseño único para las estructuras de la misión fronteriza del norte. Es una técnica que utiliza pequeñas piedras incrustadas en el yeso para crear diseños en las paredes. Hay ejemplos de esta técnica de diseño en iglesias ubicadas en el centro de México, como en la pared lateral la capilla del barrio de Nuestra Señora de los Dolores de Xaltocan, ubicado en Xochimilco (Distrito Federal). El diseño incluye una cruz flanqueada por dos flores en macetas. Un diseño festoneado como rodea a la cruz (Fig. 2).

El elemento de diseño en la fachada de la iglesia Opodepe (Fig. 3) consiste en paneles individuales con diferentes temas en las filas que originalmente flanqueaban la puerta principal de la iglesia y una ventana sobre la puerta. Modificaciones posteriores a la fachada han destruido partes del elemento de diseño. El segmento en el lado derecho de la puerta principal de la iglesia se extiende más bajo que el de la izquierda, lo que indica que el mismo, originalmente era más extenso. La incorporación de nuevos elementos de diseño por encima de la puerta y la adición de nuevas capas de yeso alrededor de la ventana también se han dañado y destruido los paneles individuales. Sin embargo, hay bastantes restos del elemento de diseño para identificar un tema general, y de los distintos elementos que parecen representar temas encontrados en petroglifos. En otras

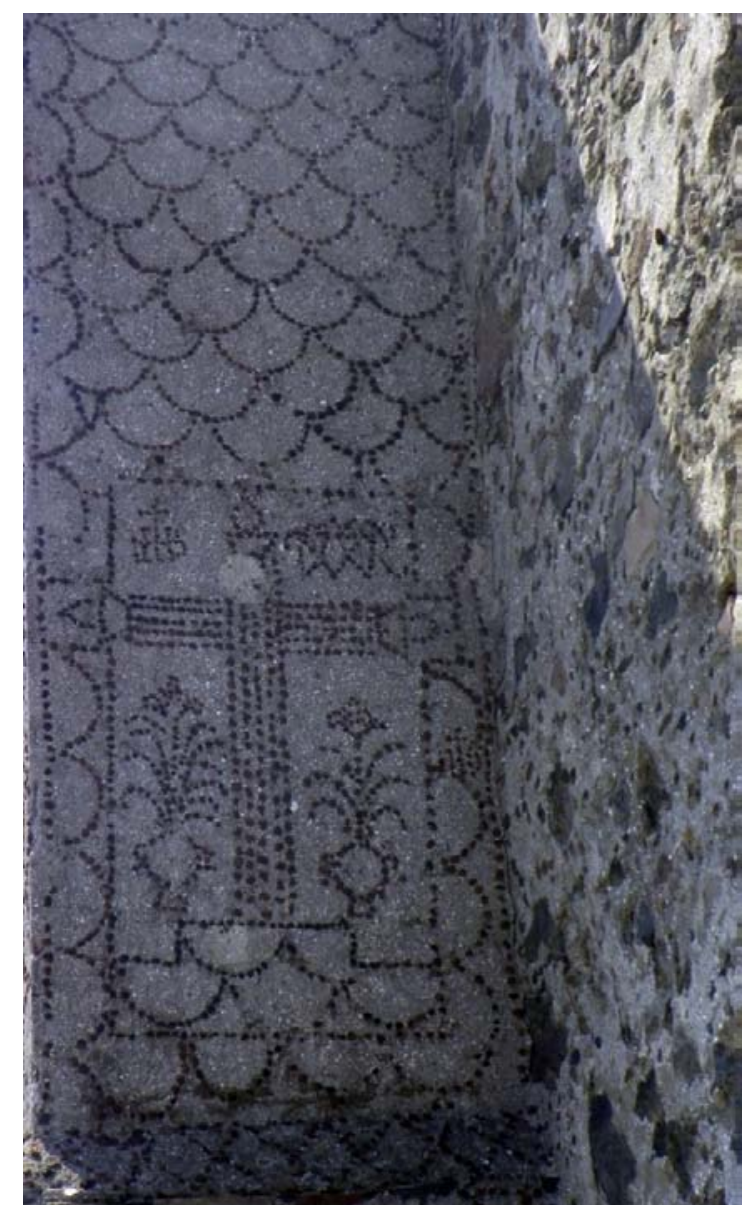

Fig. 2. Elemento del diseño en la pared lateral de la iglesia de Nuestra Señora de los Dolores Xaltocan, Xochimilco (Distrito Federal, México).

${ }^{4}$ Mirafuentes Galván, 2005: 25. 
palabras, los artistas nativos que crearon el elemento de diseño utilizaron la fachada de la iglesia para crear una serie si de petroglifos con simbolismos ligados a las creencias religiosas prehispánicas.

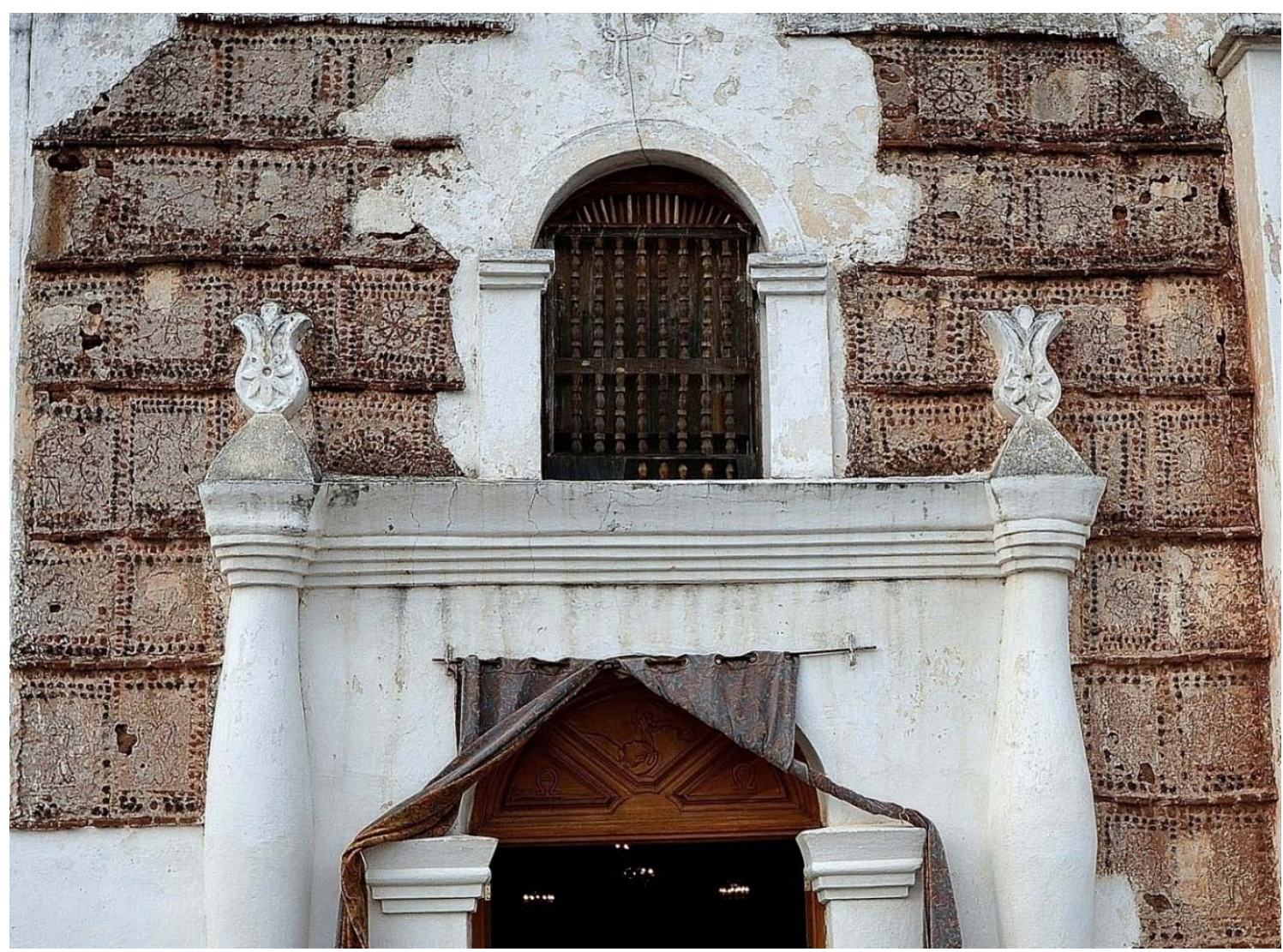

Fig. 3. Una fotografía del elemento de diseño de la fachada de la iglesia de Opodepe.

Hay varios paneles enigmáticos en el lado izquierdo y derecho del elemento de diseño que representan la deidad prehispánica de la fertilidad de Kokopelli, jugador de flauta. Un panel en el lado izquierdo representa un par de lagartos, y dos figuras en el panel adyacente. La figura de la izquierda es un ser humano y de la figura de la derecha es Kokopelli. La figura sostiene una flauta, y tiene las plumas características o antena, como salientes que emergen de la parte posterior de su cabeza. Kokopelli se representa a menudo como un jorobado, y la figura en el panel comparte esas características, aunque con diferencias físicas a la de la figura humana. Un panel que se encuentra del at lado derecho muestra un segundo Kokopelli, también identificado por las protuberancias en la parte posterior de su cabeza, tocando la flauta, y en el panel junto al sol, que era un tema común en los petroglifos prehispánicos (Fig. 4 y 5). Al menos otro panel representa Kokopelli.

Otros paneles representan temas que también se encuentran en los petroglifos prehispánicos, como un pájaro y diferentes tipos de flores, que también tenían un significado ritual. Dos paneles representan lo que parecen figuras geométricas, un tipo de flor, o tal vez un tipo de cactus y tal vez un grupo de botones de peyote (Lophophora williamsii). El peyote crece cerca del suelo y en grupos de botones individuales. Contiene alcaloides psicoactivos utilizados por chamanes nativos para provocar la búsqueda de visiones, y en el curado. Si la identificación de la figura como peyote es correcta, sería proporcionar una prueba más de la persistencia de las prácticas religiosas tradicionales en la misión. 


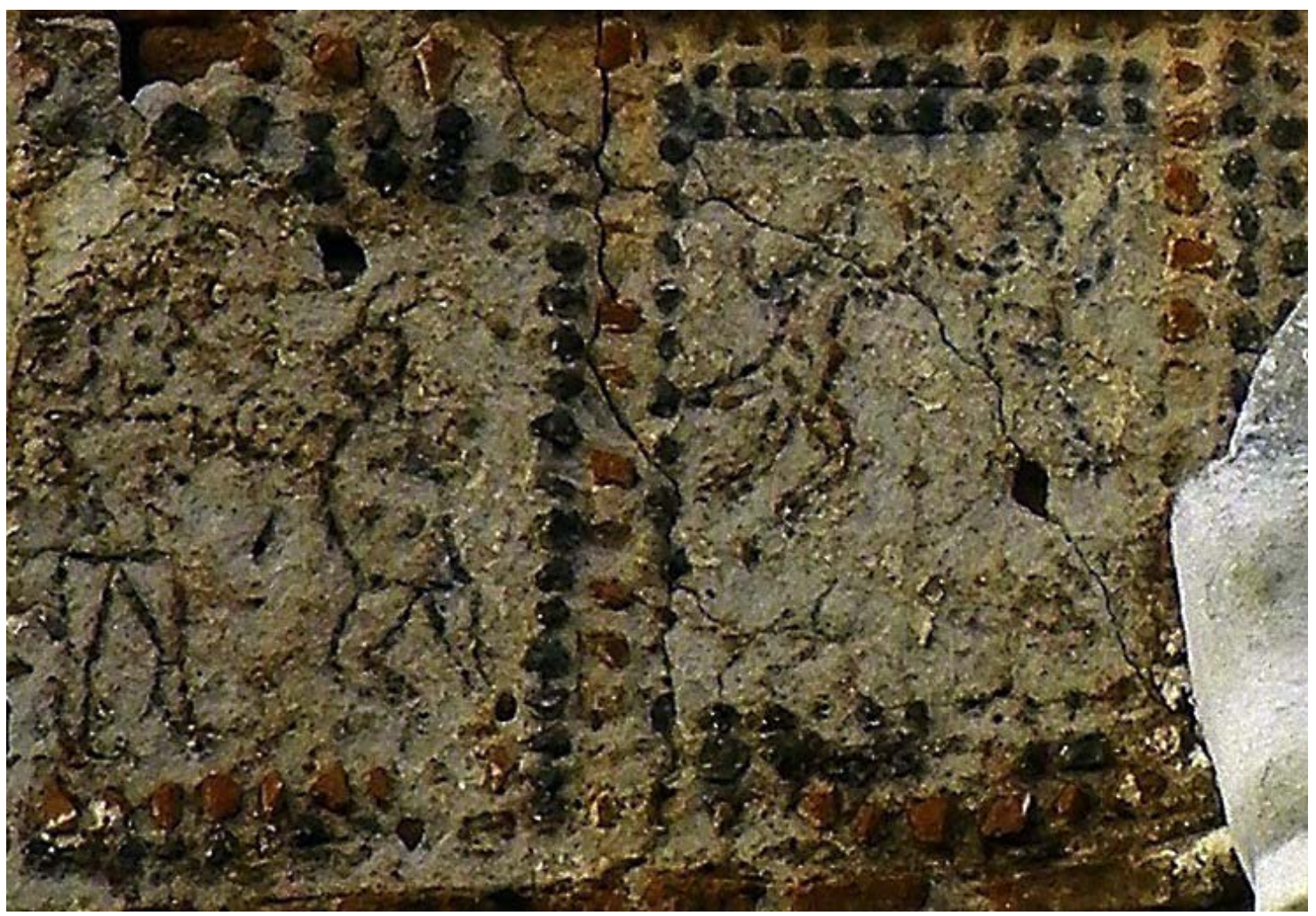

Fig. 4. Dos paneles que muestran un par de lagartos, yun ser humano y un Kokopelli.

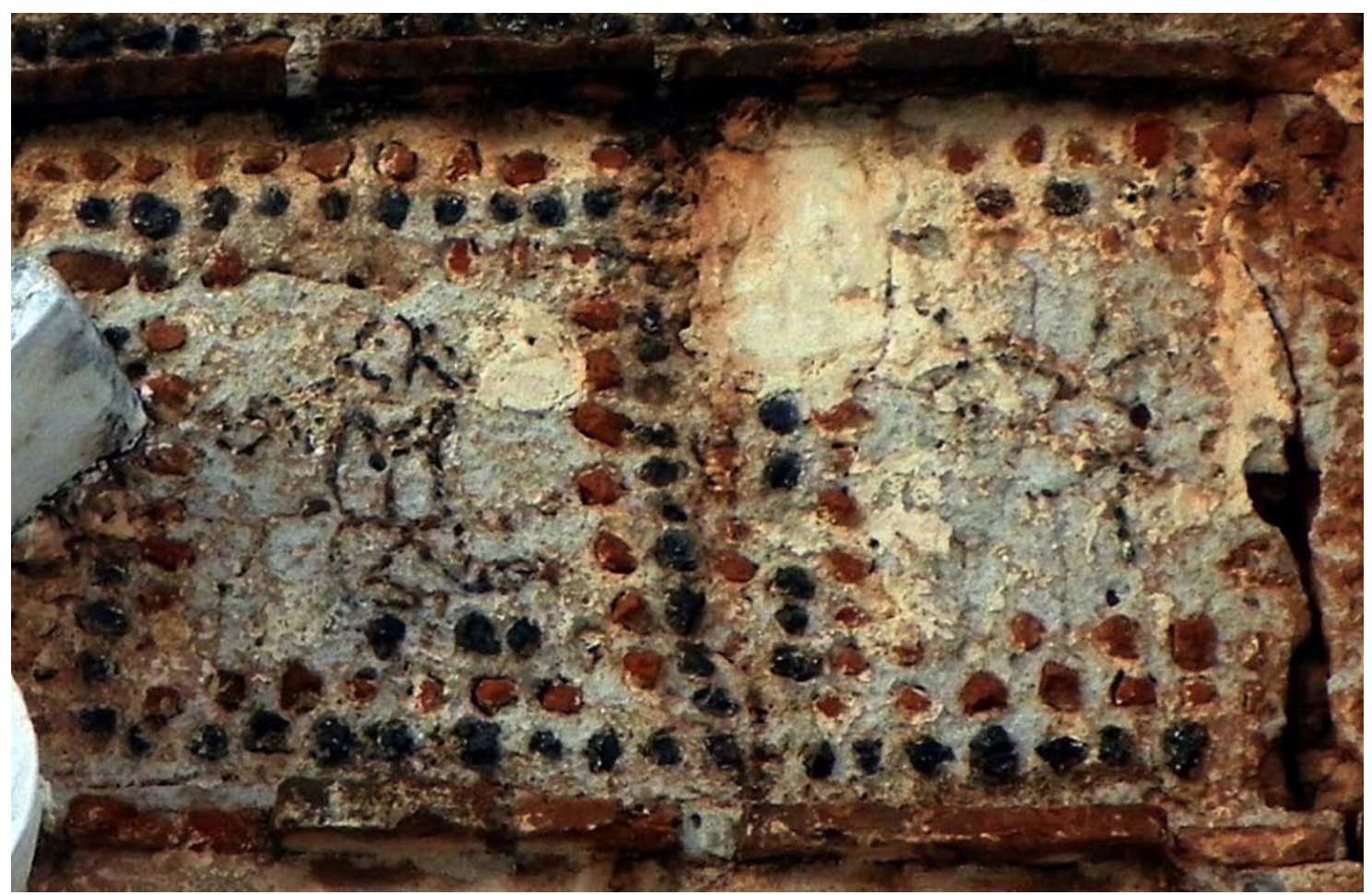

Fig. 5. Dos paneles que representan el sol y un segundo Kokopelli. 


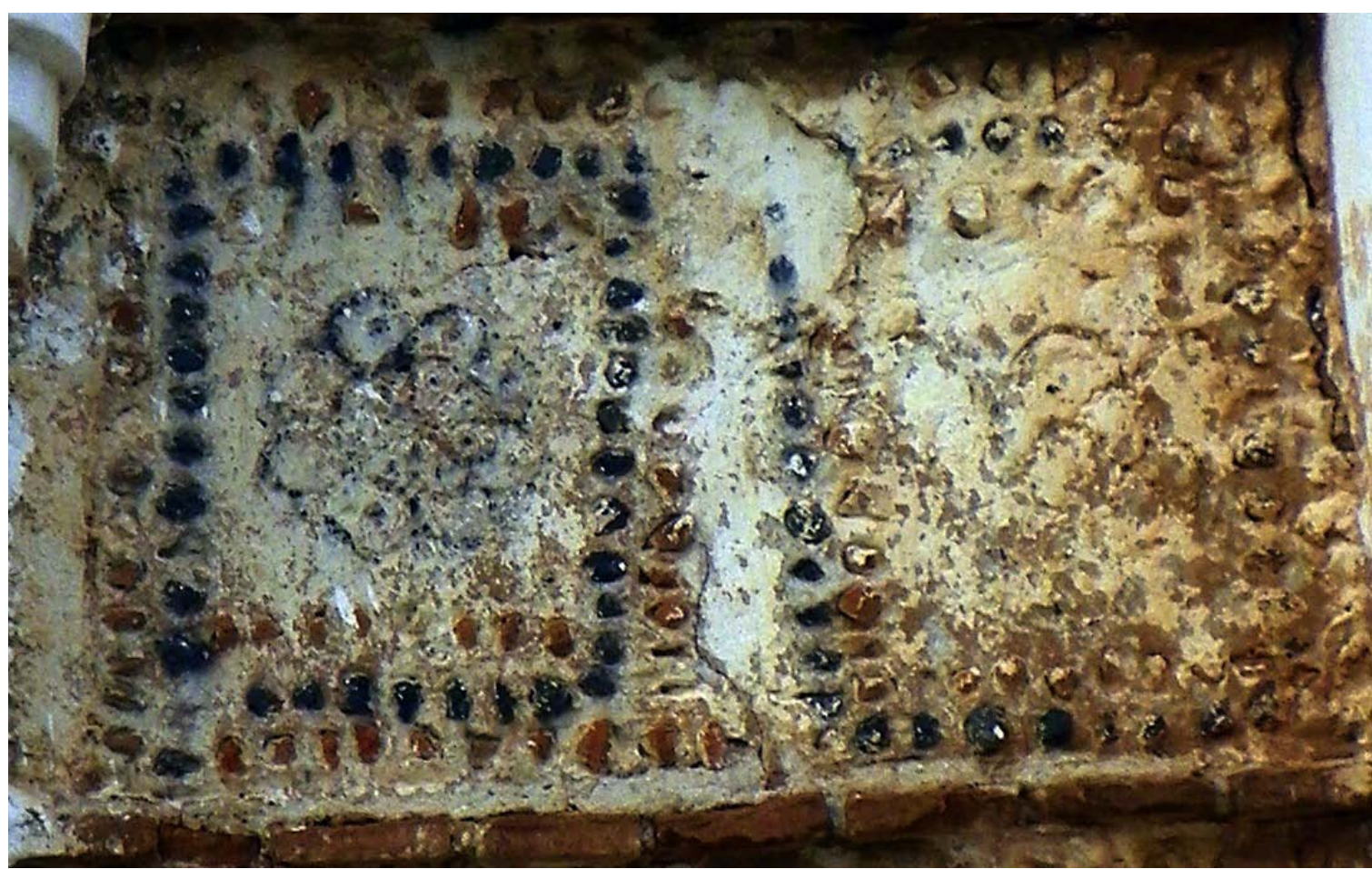

Fig. 6. Panel que muestra lo que podría ser un diseño geométrico, una flor, o un cactus y tal vez un cactus peyote.

\section{Conclusiones}

La inclusión de temas en el elemento de diseño en la fachada de la iglesia de Opodepe, también encontrados en petroglifos prehispánicos (Fig. 7-9), como la deidad de la fertilidad de Kokopelli, sugiere la persistencia en las misiones de Sonora de las creencias religiosas tradicionales junto al catolicismo. Los artistas nativos que crearon el elemento de diseño de la fachada de la iglesia Opodepe, crearon un documento visual que celebraba Kokopelli y otra iconografía prehispánica. Esto puede no haber sido el único caso de la persistencia de las prácticas religiosas tradicionales entre la Tehuima (Ópata). José Refugio de la Torre Curiel describe una danza llamada la “dagüinemaca” que se describe en documentos en el Siglo XIX. Este baile, junto con un segundo, conocido como el "jojo", incorporaba elementos culturales tradicionales como la reciprocidad. El “jojo” tenía una difusión en la memoria oral, pero también tenía un contenido milenario basado en la creencia del regreso de una figura, tal vez Moctezuma, que garantizase un futuro mejor ${ }^{5}$. Aunque forjado en la sociedad colonial y en la influencia de los misioneros jesuitas y más tarde franciscanos, no podían separarse de los valores tradicionales ligadoas a las creencias religiosas.

Kokopelli habitaba el mundo Tehuima (Ópata) en Sonora colonial. La inclusión de imágenes de Kokopelli en la fachada de la iglesia Opodepe quizás tenía la misma función que las piedras incrustadas en las iglesias del centro de México. En una religión que suelen solicitarse en dualidades, la incorporación de Tláloc o Kokopelli convirtió la nueva estructura sagrada en una compartida por una deidad prehispánica y Jesús.

\footnotetext{
${ }^{5}$ De la Torre Curiel, 2010: 189.
} 


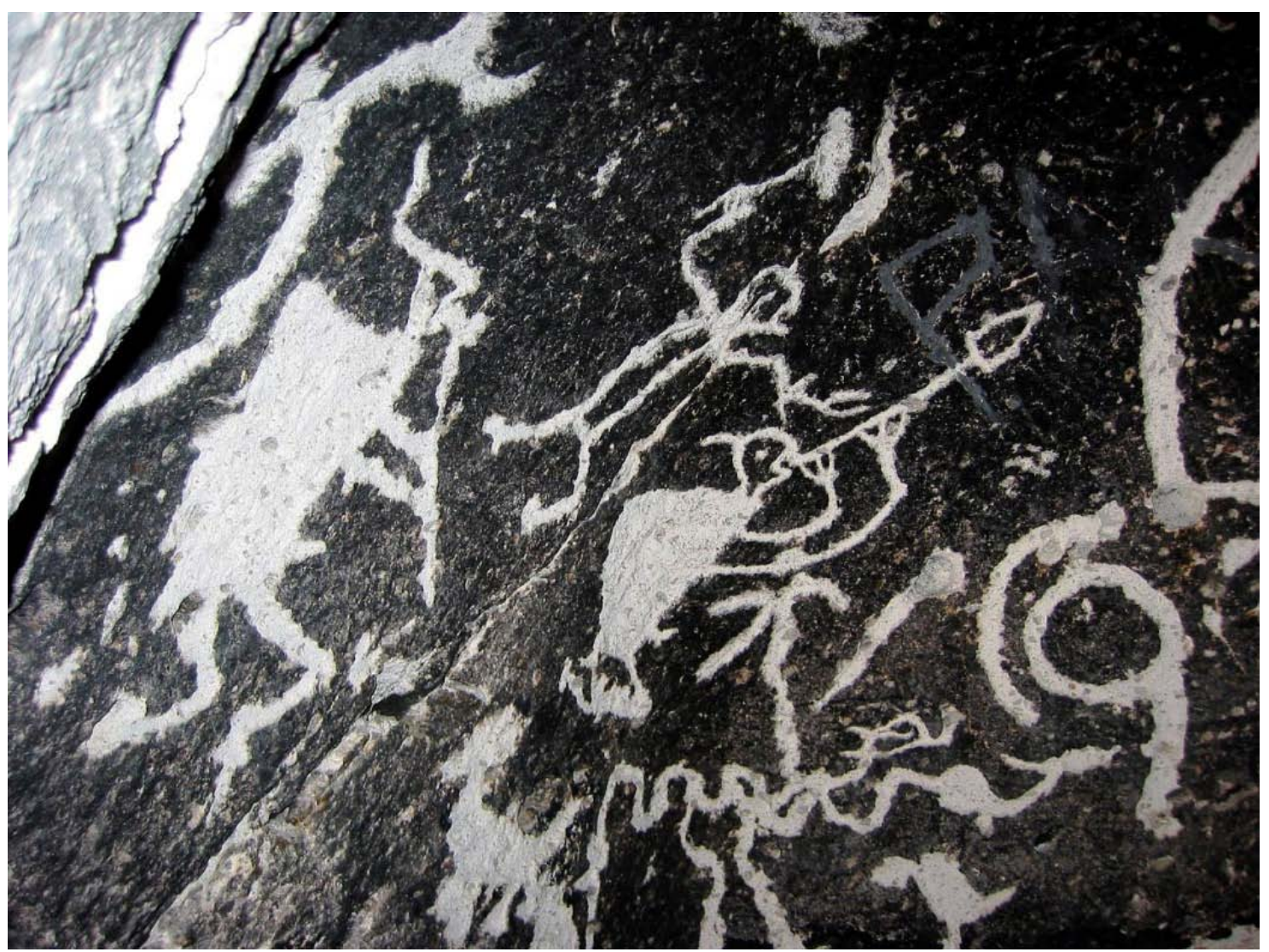

Fig. 7. Petroglifos de Kokopelli.

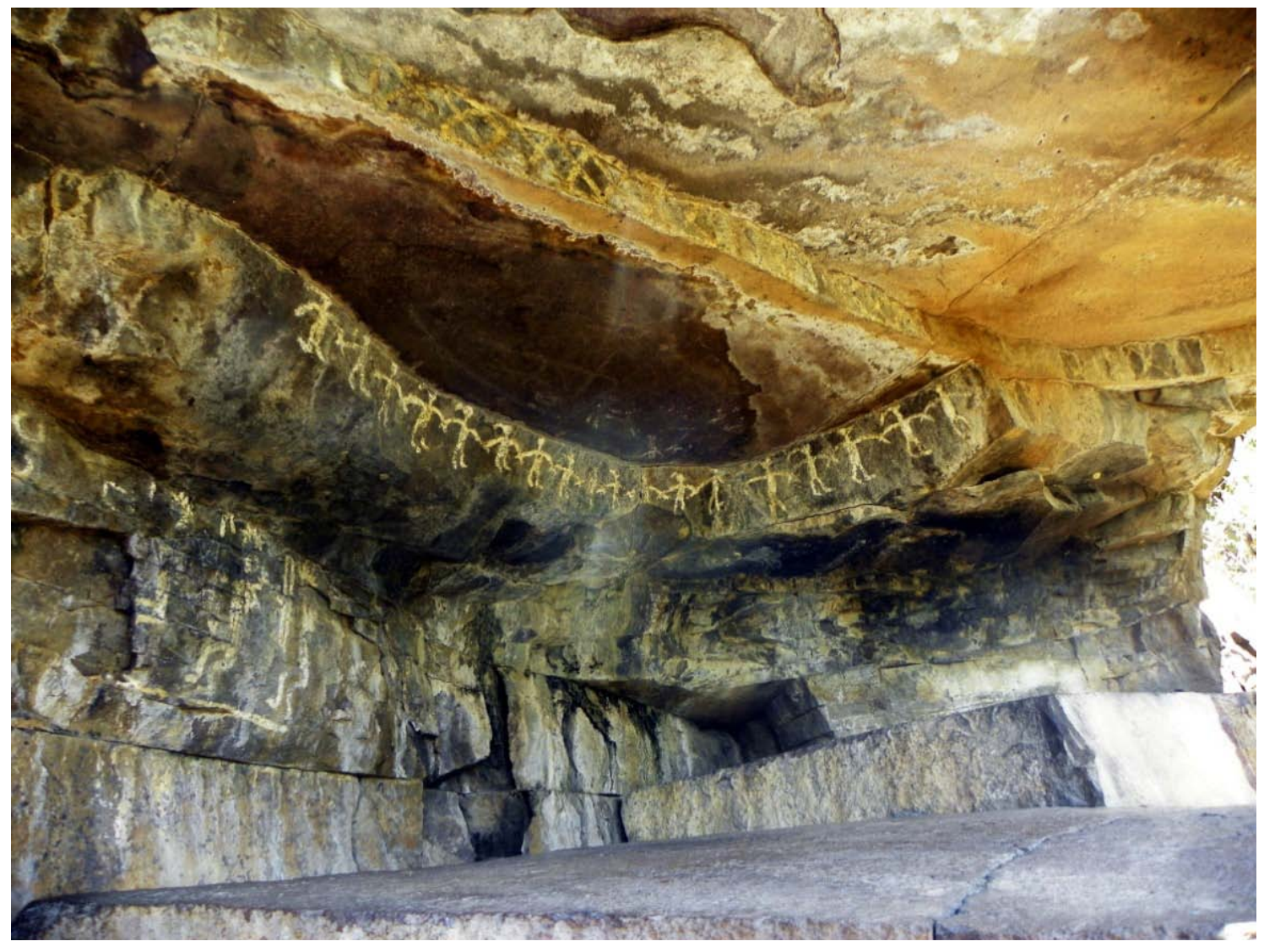

Fig. 8. Petroglifos ubicados cerca de Huichapan, Valle de Mezquital (Hidalgo). 


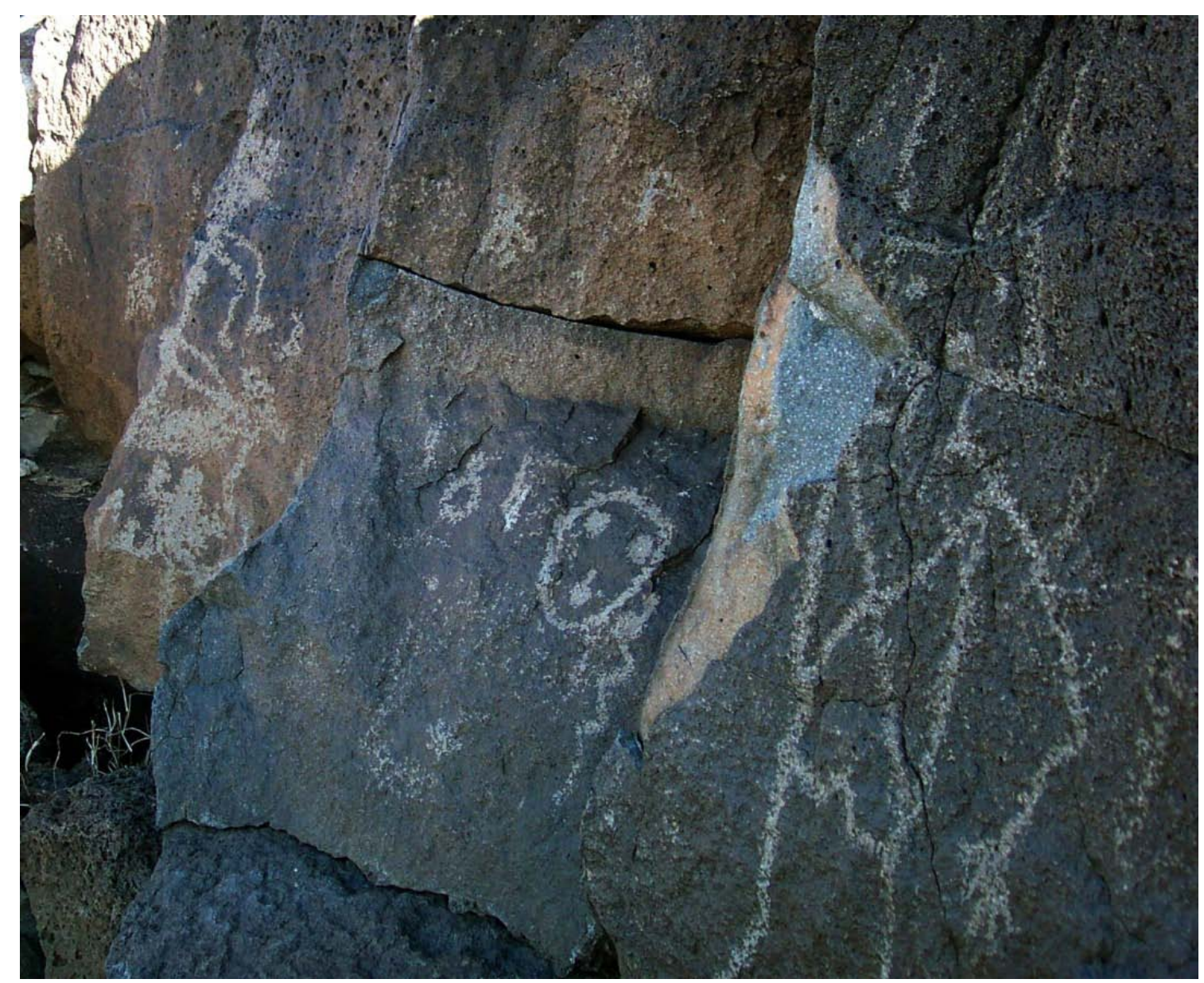

Fig. 9. Petroglifos en Nuevo México.

\section{Bibliografía}

De la Torre Curiel, José Refugio (2010), “Un mecenazgo fronterizo: El protector de indios Juan de Gándara y los Opatas de Opodepe (Sonora) a principios del siglo XIX,” Revista de Indias, vol. LXX, núm. 248.

Jackson, Robert H. (2005), Missions and Frontiers of Spanish America: A Comparative Study of the Impact of Environmental, Economic, Political, and Socio-Cultural Variations on the Missions in the Rio de la Plata Region and on the Northern Frontier of New Spain. Scottsdale: Pentacle Press.

Jackson, Robert H. (2009), “Missions on the Frontiers of Spanish America”, Journal of Religious History 33:3.

Jackson, Robert H. (2013a), “The Virgin of the Rosary at Tetela del Volcán (Morelos), Conversion, the Baptismal Controversy, a Dominican Critique of the Franciscans, and the Culture Wars in Sixteenth Century Central Mexico,” Boletin: Journal of the California Missions Studies Association 29:1. 
Jackson, Robert H. (2013b), Conflict and Conversion in Sixteenth Century Central Mexico: The Augustinian War on and Beyond the Chichimeca Frontier, Leiden, the Netherlands: Brill Academic Publishers.

Mirafuentes Galván, José Luis (2005), “Las tendencias individuales de los indios y los excesos del patrimonialism misional en Sonora, 1687-1825”, Estudios de Historia Novohispana 33 (julio-diciembre). 